\title{
Threshold Effect of Financial System on High-Quality Economic Development
}

\author{
Lu Shen (iD) and Guohua He \\ Economics and Management School, Wuhan University, Wuhan 430072, China \\ Correspondence should be addressed to Lu Shen; slevin@whu.edu.cn
}

Received 5 December 2021; Revised 14 December 2021; Accepted 22 December 2021; Published 6 January 2022

Academic Editor: Miaochao Chen

Copyright ( $\odot 2022 \mathrm{Lu}$ Shen and Guohua He. This is an open access article distributed under the Creative Commons Attribution License, which permits unrestricted use, distribution, and reproduction in any medium, provided the original work is properly cited.

\begin{abstract}
The relationship between financial system and economic development is not a simple linear relationship. In some cases, the development of finance may not improve the economic development level. This paper studies the influence of the financial system on the high-quality economic development, constructs the comprehensive index of the financial system by the factor analysis method, and calculates the green total factor productivity as the index of high-quality economic development by the CRS multiplier model. Empirically, this paper takes the panel data of 30 provinces, municipalities, and autonomous regions in China from 2005 to 2018 as samples, constructs the panel threshold model, and applies the financial system, economic development level, infrastructure, and industrial structure as threshold variables to study the nonlinear relationship between the financial system and high-quality economic development. The results demonstrate that the impact of the financial system on the high-quality economy presents an inverted U-shaped relationship when the financial system and industrial structure are the threshold variables, indicating that there is an optimal interval, that is, when the financial system threshold is between 0.1355 and 0.1377 and the industrial structure threshold is between 0.1364 and 0.1408 , the financial system plays a greater role in the allocation of funds and has the most obvious positive impact on high-quality economic development. Meanwhile, the impact of the financial system on the high-quality shows a marginal decreasing trend when the economic development level and infrastructure are the threshold variables; when the economic development threshold is less than 0.1409 and the basic setting threshold is less than 0.1167 , the financial system has the greatest effect on promoting high-quality economic development. Based on the research results, targeted policy suggestions are put forward.
\end{abstract}

\section{Introduction}

As the key of modern economy, finance plays a role in promoting high-quality economic development by reflecting and guiding the real economy to achieve the reconstitution of economic factors. According to the data released by the Central Bank, at the end of June 2021, China added loans of 12.76 trillion yuan, with a growth rate of $12.3 \%$. The balance of loans issued to the real economy was 184.54 trillion yuan, a year-on-year increase of $12.6 \%$, accounting for $61.2 \%$ of the stock of social financing scale in the same period, reflecting the strong support of monetary credit for the real economy. In the meantime, the credit structure continued to be optimized. At the end of June, the financial system steadily supported manufacturing, infrastructure, and service industries except real estate, and the growth rate of medium and long-term loans was higher than the average growth rate, reaching $41.6 \%, 17.3 \%$, and $19.1 \%$, respectively. The balance of inclusive loans to micro and small enterprises was 17.7 trillion yuan, up $31 \%$ year-on-year. The inclusive loans to micro and small enterprises supported 38.3 million small and microbusiness entities, with a year-on-year increase of 29.2\%. The People's Bank of China has also pioneered the use of funds from Central Bank to encourage commercial banks to "maximally extend" inclusive loans to micro and small enterprises. By the end of June, the national banking financial institutions had issued 6.9 trillion yuan of inclusive loans to micro and small enterprises. In addition, the financial support for scientific and technological innovation continues to increase. As of the end of June, the loan balance 
of small and medium-sized high-tech enterprises was 2.86 trillion yuan, with a year-on-year increase of $19.96 \%$. The loan rate of small and medium-sized high-tech enterprises was $41.8 \%$, and the loan balance increased by $8.75 \%$ compared with the beginning of the year. Moreover, with the implementation of the new Securities Law and the reform of the registration system, the IPO rate of enterprises has steadily increased. In 2020, a total of 396 new shares of A-shares were listed, with total financing of 469.963 billion yuan, a record high of nearly 10 years. The number of IPOs and the amount of financing increased by $95 \%$ and $86 \%$, respectively. The Science and Technology Innovation Board and the Growth Enterprise Board provided financing of 311.917 billion yuan in total for science and technology enterprises, accounting for $66.4 \%$ of the total financing amount of A-share IPOs. This manifests the contribution of capital market to technological innovation.

The important function of finance lies in allocating capital to projects with high marginal efficiency, promoting capital from industries with low productivity to industries with high productivity, and improving the allocation efficiency of capital. The "14th Five-Year Plan" is a crucial period for China to achieve the goal of highquality economic development. In the 15 major work measures put forward in by the Fifth Plenary Session of the 19th Central Committee in the Central Committee of the Communist Party of China's Proposal on Formulating the 14th Five-Year Plan for National Economic and Social Development and the Long-Term Goals for 2035, it clearly pointed out the needs to build a financial service system that can effectively support the real economy, improve the financial support innovation system, build a green financial system to support green and low-carbon economic development, promote two-way financial opening, encourage competition, adhere to the inclusive finance, and improve the rural financial service system. These goals further highlight the significance of the financial system to high-quality economic development at present and in the future and identify the important direction for the financial system to support high-quality economic development.

To strengthen the financial system's support for highquality economic development, relevant policies, schemes, and management measures have been formulated throughout the country. For example, in 2021, Xi 'an Branch of the People's Bank of China took the lead in issuing Guiding Opinions on Financial Support for High-Quality Development of County Economy, aiming at giving full play to the role of county financial organization system in highquality economic development. In 2020, Hunan Provincial Local Financial Supervision and Administration issued the Implementation Opinions on Accelerating the High-Quality Economic Development with the Strategy of "Three Highs and Four News" in Financial Services, so as to step up the construction and improvement of modern financial service system adapted to Hunan's new development stage. In 2021, Hangzhou Municipal Government formulated Several Measures for Financial Support to Serve the High-quality Development of the Real Economy, aiming at promoting the high-quality development of the real economy, deepening the reform of the financial supply side, and enhancing the capacity of the financial sector to serve the real economy. In 2021, Nantong Municipal People's Government issued Several Policy Opinions on Promoting Financial Support for Industrial Transformation and Upgrading, aiming at giving full play to the support of multilevel financial markets for technological innovation and industrial transformation, expanding the contribution of financial policies to local economy and facilitating the high-quality development of the city's economy.

However, the relationship between the financial system and economic development is not a simple linear relationship. In some cases, the development of finance may not improve the economic development level. A typical fact is that China's financial industry entered a period of great development after the global financial crisis in 2008, and the added value of the financial industry in GDP kept rising, even surpassing the level of the United States. However, as we all know, China's GDP growth rate in the same period remained at a relatively high level except in 2010 and 2011. Since 2012, it has presented an evident downward trend for many years. Can the existing financial system effectively promote the high-quality development of Chinese economy? What is the relationship between them? Is there an optimal financial system suitable for high-quality economic development? What are its characteristics? This is the concern of this article.

Hence, this paper discusses the optimal financial system suitable for high-quality economic development and explores the influence of high or low financial system on highquality economic development and introduces threshold effect to analyze the nonlinear relationship between them.

The contributions of this article can be summarized as follows:

First: the green total factor productivity with multiple input and multiple output, expected output and nonexpected output, energy and environment, and so on is constructed as an index measuring high-quality economic development, and it is more in line with the economic characteristics that China's economic growth rate is slowing down and entering the stage of highquality economic development.

Second: compared with national macrodata, the results obtained through provincial data are more stable and have stronger guiding significance for regional economic development in China.

Third: in the empirical aspect, panel threshold model is adopted, and threshold variables such as financial system, economic development level, infrastructure, and industrial structure are constructed to explore the influence and mechanism of financial system on highquality economic development from multiple angles.

The rest of this article is organized as follows. Section 2 presents literature review. Section 3 discusses the theoretical hypotheses. Section 4 designs this research. In Section 5, an empirical analysis is carried out. Section 6 summarizes the full text. 


\section{Literature Review}

2.1. The Argument of Financial System Promoting or Restraining Economic Growth. Many research studies have been carried out on the financial system and economic growth. Some scholars believe that the financial system can effectively promote economic growth. Schumpeter [1] theoretically demonstrated that the financial system can promote economic growth by reducing transaction costs and information costs. Since then, the relationship between the financial system and economic growth has attracted the attention of academic circles. Patrick [2] holds that financial development is a subsidiary of economic growth, and there is a parallel relationship between financial development and economic growth. Goldsmith [3] thinks that the rapid economic growth is accompanied by the rapid financial development, while the economic downturn will lead to the decline of financial development. Financial development and economic growth share synchronous progress and belong to a parallel relationship. Mckinnon [4] thinks that the development of finance, especially the development of financial intermediaries, increases the accumulation of capital and reduces the cost of capital, thus increasing social savings and promoting economic growth. Beck et al. [5] put forward that the essence of the financial system promoting economic growth lies in the innovative development of finance, and an innovative financial system can enhance the credit support for technology enterprises, promote technological innovation and development, and further increase productivity.

However, other scholars believe that the financial system is ineffective for economic growth, and there is a negative correlation between the development of the financial system and economic growth. From the perspective of the financial system itself, Sun et al. [6] believe that the development of China's financial system pays more attention to the development of scale and form and confronts severe fragility, which restricts the contribution of bank credit to economic development and application. Marco [7] considers that insufficient understanding of the emergence and development of financial markets may lead to factors that reduce the savings rate in the economic system, which is not conducive to economic growth. From the perspective of financial development, Palley [8] believes that financial development will lead to the transfer of income from the real sector to the financial sector, and economic growth will be hindered with the increase of income inequality and debt tightening. Lorenzo and Grechyna [9] employed the panel data of 101 countries and discovered that the economic growth will be impeded if the financial development is too advanced and separated from the growth rate of the real economy. Oluitan [10] analyzed the impact of financial liberalization and believed that financial liberalization will trigger financial turmoil. He concluded that financial development is not conducive to economic growth, and finance exerts a restraining effect on economic growth. Zhang [11] thinks that the insufficient coordination between financial development and technological innovation will affect the economic development.
2.2. There Is a Nonlinear Relationship between Financial System and Economic Growth. With the continuous advancement of research on financial system and economic growth, different financial markets and financing methods will have varying impacts on economic growth, and there is a nonlinear relationship between financial system and economic growth. From the perspective of national development level, Kabir et al. [12] concluded through empirical research that the financial system has a positive promoting effect on economic growth in low and middle-income countries, while it has a restraining effect in high-income countries. Lin and Yang [13] found that from the perspective of developed countries, financial stability depends on overseas securities investment, bond investment, and real interest rate, and the rise of these indexes will bring economic growth; From the perspective of emerging market countries, the financial stability depends on the ratio of foreign debt to GNP and the ratio of international reserves to foreign debt, and the increase of these two indexes will lead to the decline of economic growth rate, whereas the increase of the ratio of total savings to GDP and the ratio of trade volume to GDP will promote financial stability, thus driving economic growth. From the perspective of financial structure, Allen and Gale [14] concluded that the market-led financial structure has more advantages than the bank-led financial structure because the market-led financial structure is more flexible in resource allocation and more reasonable in risk management, which is conducive to enterprise innovation, so the influence on economic growth is based on the dominant financial structure. Eschenbach [15] believes that the key to promoting economic growth depends on the level of financial services and the health of the financial system, and only a developed banking system and an active capital market are beneficial for economic growth. From the perspective of development stage, Boyd and Smith [16] found that the differences of financing modes have different effects on economic development in different stages. Hicks [17] thinks that only a strong financial system can promote technological innovation with the development of finance, which suggests that only when finance develops to a certain stage can it contribute to economic development. Chen et al. [18] discovered that the instability of the financial system plays a different role in different stages of economic growth, and the asymmetric influence exists. From the perspective of influence path, Yang et al. [19] believe that financial resources affect economic growth through two ways: the input scale of production factors and the rate of technological progress, but there is a "seesaw" relationship between the two influences. Hung et al. [20] think that investment loans are beneficial to economic growth, while consumption loans are detrimental to economic growth. However, because financial development promotes consumption loans and investment loans simultaneously, the ratio of the two determines the result of financial development on economic growth, so there is a nonlinear relationship. Some scholars consider the nonlinear mechanism of the financial system to economic growth, but they are primarily based on the different dimensions of the financial system itself [21]. 
2.3. There Is a Threshold Effect between Financial System and Economic Growth. Based on the nonlinear relationship between them, some scholars have studied the threshold effect between them. In terms of taking financial development as the threshold variable, Zilibotti [22] thinks that transaction cost and operation cost will be lowered when finance develops to a certain threshold value due to the existence of scale effect, which also makes enterprises easier to obtain financing, helps technological innovation, and achieves economic growth, so financial development has a threshold effect on technological progress. Yang [23] took the level of financial development as the threshold variable and concluded that financial development shows nonlinear characteristics of threshold effect and diminishing marginal efficiency on economic growth. In addition, the threshold value in the western region is higher than that in the central region, while that in the central region is higher than that in the eastern region. Liu et al. [24] believe that the level of financial development has a threshold value for economic growth, and only after reaching this threshold value can it improve the level of financial development, alleviate the "resource curse," and promote economic growth. Mihci [25] found that it will not promote the economy obviously when the development level of the financial industry is lower than the threshold, and only when it is higher than the threshold can it fully play its role. Deidda [26] thinks that it cannot meet the cost of manpower, material resources, and financial resources required by the whole financial market when the financial development is below the threshold value, which will lead to the financial market making ends meet, thus affecting economic growth. While taking external factors as threshold variables, Graff and Karmann [27] took available funds as influencing factors and drew the conclusion that when people's motivation for saving is reinforced if financial development reaches the threshold value, this leads to the increase of social available funds, thus promoting economic growth. Rousseau and Wachtel [28] hold that inflation has a threshold effect on financial development. When inflation exceeds the threshold, the effect of financial development on economic growth weakens. Prasad et al. [29] also studied the threshold effect between financial globalization and economic growth and found that it will contribute to the development of financial globalization when financial governance is improved. Bekaert et al. [30] think that the improvement of the financial market will help to improve the productivity when the financial openness reaches the threshold. Zhang et al. [31] analyzed the relationship between regional financial strength and real economic growth with regional financial strength as the threshold variable and concluded that the improvement of regional financial strength can promote the real economic growth. Luo [32] studied the threshold effect of FDI indirectly affecting economic growth through total factor productivity, domestic investment, and human capital while taking financial development as the threshold variable, and FDI affects economic growth through different channels because of different degrees financial development. From the perspective of double threshold effect, Liu and Li [33] found that financial fluctuation has double threshold effect on economic growth, and the tolerance elasticity of economic growth for financial fluctuation will shift with the stage of financial cycle. Zhang and Wang [34] applied the double threshold regression test and discovered that there is imbalance between regional finance and economic growth in China, which reduces the resource allocation capacity of financial market, and excessive deviation of financial development will inhibit the growth of real economy.

The aforementioned review shows that there is no consensus on the research of the relationship between the financial system and economic growth in the existing literature, and most of the economic growth indexes are measured by GDP and other related indexes. At present, China's economy is entering a new stage of high-quality economic development, and a single economic growth index such as GDP can hardly reflect the new characteristics of high-quality economic development. Moreover, the existing literature mainly uses macrodata at the national level (Sun et al. [6] and Lin and Yang [13]), which has limited guiding significance for China's regional economic development.

\section{Theoretical Hypotheses}

Economists represented by John Gurley formulated the financial development theory in the 1950s and believed that the inefficient operation of the financial system and the backward financial development are the reasons for inhibiting the economy. Subsequently, Shaw Edward concluded in his book Financial Structure and Economic Development that financial development is an important condition to promote economic growth, and the higher the stage of economic development, the stronger the role of the financial system. The financial system can accelerate technological progress through liquid financial assets. On the one hand, the financial system can guide enterprises to choose technologies with high potential productivity and promote enterprises to invest in high-risk technological innovation fields. On the other hand, the financial system can provide enterprises with various financing ways to cope with the uncertain risks brought about by technological innovation. The financial system can also complement resources by absorbing foreign technology and integrating upstream and downstream resources, thereby promoting the development of technology. Hence, it better serves the high-quality development of economy by developing an effective financial system, avoiding the blind deepening of finance and matching with the characteristics of scale, risk and factor endowment, etc.

The financial systems corresponding to different economic growth stages are different in size and structure. At the initial stage of economic development, the demand for finance is single. With the improvement of economic level, the requirement for perfection of the financial system is getting increasingly higher. Extensive infrastructure construction can no longer satisfy the needs of economic transformation. The financial system should provide more complex financial services to better meet the upgrading of industrial structure in the context of the optimization of industrial structure. Only a financial system that is suitable 
for economic development level and industrial structure can effectively facilitate sustained and high-quality economic development. Therefore, this paper constructs threshold variables such as financial system, economic development level, infrastructure, and industrial structure and further studies the influence and mechanism of financial system on high-quality economic development from multiple angles.

\subsection{Financial System and High-Quality Economic} Development. The financial system has the basic functions of risk diversification, financing, supply liquidity, and so on. Most of the real markets are imperfect competition markets, and there are some restrictive factors such as asymmetric information and insufficient market effectiveness. Whether the financial system is sound and can play its basic functions is the decisive factor to measure whether the financial system can promote economic growth [6]. This is reflected not only in the financing of microfinancial institutions to enterprises but also in the mobilization of surplus and shortage of funds in macrofinancial markets to achieve the optimal allocation of factors. Meanwhile, it is also reflected in financial asset prices, real estate prices, and eventually in the stability of the macrofinancial system. Since the reform and opening-up, China's economy has achieved rapid growth, and the financial system has undergone many reforms from highly centralized and single financial institutions to a diversified financial system with more market-oriented and richer financial services and means. During this period, the reform and development of the financial system is gradually adapted to the economic development, giving full play to the basic functions of the financial system. This will inevitably play a role in promoting economic growth. When the financial system is gradually improved and the financial legal framework and financial macrocontrol are increasingly mature, the role in promoting economic growth will reach its maximum. With the economic growth entering the new normal, the high-quality economic development lays emphasis on the steady growth of structure rather than the pursuit of the growth rate and total amount, and the financial development also presents new features, such as the collapse of P2P and Internet load, and so on. Due to the lag of supervision and financial laws, it has caused huge negative impact on the economy.

$\mathrm{H} 1$ : when other variables are controlled, the impact of financial system on the high-quality economy presents an inverted U-shaped trend.

3.2. Financial System, Economic Development Level, and High-Quality Economic Development. The volume and structure of the financial system should be adapted to the stage of economic growth to meet the needs of economic growth [35]. Different stages of economic growth have different levels of economic development. In the early stage of economic development, the demand for finance is single, and bank credit is the main body in the financial market. By regulating capital elements, financing is realized. Correspondingly, the financial risk is relatively small. At this time, the financial system is adapted to the stage of economic development, and the financial system can better promote economic development. With the improvement of economic development, the number of natural persons and legal persons who need financing in the market increases, and the adverse selection and moral hazard caused by information asymmetry when financial institutions identify the credit situation of credit demanders are increasing. In this context, the financial risk increases, and the credit market and capital market show fragility [6], thus reducing the impetus to economic development.

$\mathrm{H} 2$ : when the economic development level is taken as the threshold variable, the impact of the financial system on the high-quality economy shows a diminishing marginal trend.

\subsection{Financial System, Infrastructure, and High-Quality Eco-} nomic Development. Spatial economic linkages are characterized by interactions and relationships among economic entities and regions, and the intensity of linkages has an important impact on the overall economic vitality of a region [36]. At the early stage of social development, the infrastructure is not perfect, and the infrastructure construction focusing on the investment and financing in transportation infrastructure is the precondition of economic development [37]. Along with the increase of investment and financing in infrastructure, the facilities are gradually improved, which connects various regions, reduces transportation costs, and accelerates the flow of production factors in the region. When the infrastructure is improved to a certain extent, the financial system's role in promoting the economy will increase, and further the role in promoting the economy will gradually decrease, demonstrating a diminishing marginal trend.

H3: when the infrastructure is taken as the threshold variable, the impact of the financial system on the highquality economy shows a diminishing marginal trend.

\subsection{Financial System, Industrial Structure, and High-Quality} Economic Development. The continuous optimization of industrial structure has a significant intermediary effect on high-quality economic development [38]. In the initial stage of industrial development, the industry has achieved certain development with the support of financial capital, which has a promoting effect on economic development. When the financial system is playing its basic functions, low-efficiency enterprises and inferior industries cannot obtain financial support, so they may go bankrupt in market-oriented competition or may be forced to reform and transform into high-efficiency enterprises and high-quality industries [39]. In this regard, the financial system has a great role in promoting high-quality economic development. With the industrial agglomeration and upgrading, the scale of enterprises increases, and the risks they face will increase accordingly. If the financial system does not innovate financial products to meet the financial services and needs of industrial structure upgrading and enterprise diversification, it cannot match the development of industrial structure, and its role in promoting economic development will be mitigated. 
H4: when the industrial structure is taken as the threshold variable, the impact of the financial system on the high-quality economy presents an inverted U-shaped trend.

\section{Research Design}

\subsection{Variable Selection and Data Source}

\subsubsection{Explained Variable}

High-Quality Economic Development. The 19th National Congress of the Communist Party of China put forward "establishing and improving the economic system of green and low-carbon circular development," which sets out the goal for high-quality economic development. The Ninth Plenary Session of the 14th Central Committee of the Communist Party of China pointed out that improving the total factor productivity can accelerate the high-quality economic development. Green total factor productivity is the most effective comprehensive index to measure highquality economic development in the context of economic transformation. Therefore, this paper selects the green total factor productivity as the proxy variable of high-quality economic development and adopts DEA-Malmquist-Luenberger index method to measure the green total factor productivity. This method can measure more input and more output. In the meantime, it can also include both expected output and unexpected output. It can measure the green total factor productivity more comprehensively and reflect the high-quality economic development (see Table 1 for the construction of specific indexes).

Table 1 shows the selection of the input and output indexes of green total factor productivity, and this paper selects three inputs: fixed assets, human capital, and energy. Among them, the fixed asset investment refers to the practice of Zhang et al. [40]. First, the index of the fixed asset investment is converted into the stock of fixed assets through the perpetual inventory method. The actual calculation runs as follows: $K_{i t}=I_{i t}+(1-\delta) K_{i t-1}$, where $K_{i t}$ is the capital stock of province $i$ in the year $t, I_{i t}$ is the amount of fixed asset investment of province $i$ in the year $t$, and $\delta$ is the depreciation rate (here, it is set at 6\%). 2004 is the base year, and the amount of its fixed asset inventory is calculated via $K_{i 0}=I_{i 0} /(g+\delta)$, after consulting Coe and Helpman [41]. $K_{i 0}$ is the base year's capital asset, $g$ is the economic growth rate of that year, and $\delta$ is the depreciation rate, calculated by running deflator on each province's fixed asset investment price index of that year. The index of human capital investment is calculated based on two indicators: the amount and the quality. The amount of human capital is the sum of each province's labour force working in the primary, secondary, and tertiary industries. The quality of human capital is calculated according to the years of education one has received, i.e., $S=\sum S_{i} L_{i} / \sum L_{i}$. In this formula, $S$ is the maximum number of years receiving education for a given level, and $L$ is the number of people receiving each level of education. Education years in each stage are 6 years in primary school, 3 years in junior middle school, 3 years in senior middle school, and 3 years in higher education. In terms of output selection, this paper selects the expected output and the unexpected output, respectively, in order to measure the high-quality economic development more accurately. The expected output adopts the regional GDP commonly used in the literature, which is also deflated according to the GDP deflator of the corresponding year. The unexpected output selects five indexes: waste water, chemical oxygen demand discharge, ammonia nitrogen discharge, sulfur dioxide discharge, and total dust discharge, among which the total dust discharge consists of industrial smoke (powder) dust discharge and domestic smoke (powder).

\subsubsection{Core Explanatory Variable}

Financial System. Sun et al. [6] only described financial fragility from the perspective of financial risk, which cannot reflect the essence of the problems in China's financial field. Whether the financial system plays its basic functions is the decisive factor to measure whether the financial system can promote sustained economic growth. On the basis of $\mathrm{Li}$ [42] and other studies, this paper constructs the comprehensive index of financial system based on macroeconomy, macrofinancial institutions and markets, and microfinancial institutions and markets (see Table 2 for the specific indexes). In the setting of weights, the factor analysis method is firstly employed to build the weights of the three subindexes, and then the weights of the three indexes are summed up.

4.1.3. Threshold Variables. Financial system (FCF): this index is also the core explained variable of this paper. The construction method will not be described again. The economic development level (AGDP): the proxy index of per capita GRP obtained by the ratio of GRP to the total number of people in the region. Infrastructure (RPC): the proxy index of per capita road area index obtained by the ratio of the total road area to the total number of people in the region. Industrial structure (IDL): it is measured by the ratio of the tertiary industry to the secondary industry, using the common practice in the literature.

4.1.4. Control Variables. Investment rate (ITR): the ratio of total regional fixed assets to GRP. Population growth rate (PGR): the ratio of the regional population of this year and the previous year. Urbanization rate (UBR): the ratio of urban population in the total population of the region. Industrialization rate (IDR): the ratio of the secondary industry to the primary industry. Table 3 illustrates the descriptive statistics of variables.

4.1.5. Data Source. The data in this paper are provincial data, which come from China Statistical Yearbook, Environment Statistical Yearbook, China Science and Technology Statistical Yearbook, the website of National Bureau of Statistics, and ESP database.

Due to the lack of data in Tibet Autonomous Region, the data of 30 provinces (autonomous regions and 
TABLe 1: Descriptive statistics of input and output variables.

\begin{tabular}{|c|c|c|c|c|}
\hline Variable & Mean value & Maximal value & Minimal value & Standard deviation \\
\hline Capital stock & 61767.1 & 339017.2 & 2813.0 & 57918.4 \\
\hline Quantity of human capital & 2556.3 & 6822.0 & 263.1 & 1681.6 \\
\hline Quality of human capital & 8.2 & 11.7 & 6.2 & 0.8 \\
\hline Total energy & 4960.0 & 28679.2 & 270.3 & 4167.0 \\
\hline Electricity consumption & 1490.8 & 6090.4 & 68.7 & 1182.9 \\
\hline Water consumption & 197.6 & 591.3 & 22.1 & 139.5 \\
\hline GRP & 11710.4 & 582315.2 & 440.1 & 16276.8 \\
\hline Waste water & 210371.7 & 938261.0 & 14287.0 & 167020.3 \\
\hline Chemical oxygen demand discharge & 53.8 & 198.3 & 3.2 & 39.2 \\
\hline Ammonia nitrogen discharge & 5.69 & 23.1 & 0.5 & 4.1 \\
\hline Sulfur dioxide discharge & 65.7 & 200.2 & 1.3 & 43.9 \\
\hline Total dust discharge & 43.5 & 193.7 & 1.6 & 91.2 \\
\hline
\end{tabular}

TABLE 2: Construction of financial system indexes.

\begin{tabular}{lc}
\hline $\begin{array}{l}\text { Construction of financial system } \\
\text { index }\end{array}$ & Subindex \\
\hline Macroeconomy & Economic growth rate \\
\hline $\begin{array}{l}\text { Macrofinancial institutions and } \\
\text { markets }\end{array}$ & $\begin{array}{c}\text { Financial deficit/GDP } \\
\text { Total amount of credit/ } \\
\text { GDP }\end{array}$ \\
\hline $\begin{array}{l}\text { Microfinancial institutions and } \\
\text { markets }\end{array}$ & $\begin{array}{c}\text { Loan balance/deposit } \\
\text { balance }\end{array}$ \\
& $\begin{array}{c}\text { Real estate value/GDP } \\
\text { Nonperforming ratio }\end{array}$ \\
\hline
\end{tabular}

municipalities directly under the Central Government) from 2005 to 2018 are retained as research samples after excluding the data of Tibet Autonomous Region. A small number of missing data are supplemented by the interpolation method and regression method.

4.2. Model Construction. To explore the role of financial system in high-quality economic development, the following econometric models are firstly constructed to verify the matching between the variable of financial system variable and the variable of high-quality economic development:

$$
\mathrm{TFP}_{i t}=\beta_{1} \mathrm{FCF}_{i t}+\beta_{2} Z_{i t}+\xi_{i t}
$$

where $i$ represents province; $t$ represents year; $\mathrm{TFP}_{i t}$ represents high-quality economic development; $\mathrm{FCF}_{i t}$ represents financial system; $Z_{i t}$ represents set of control variables, namely, investment rate (ITR), population growth rate (PGR), urbanization rate (UBR), and industrialization rate (IDR); and $\xi_{i t}$ is a random disturbance term.

The research of Sun et al. [6] and Chen et al. [18] concludes that there may be a nonlinear relationship between the financial system and the high-quality economic development. Hence, according to the nonlinear panel threshold model of Hansen [43], this paper constructs an econometric model, and the single threshold model is set as follows:

$$
\begin{array}{ll}
\mathrm{TFP}_{i t}=\alpha_{0}+Z_{i t} \beta_{1}+\theta_{1} \mathrm{FCF}_{i t}+\mu_{i}+\xi_{i t}, & \text { if } q_{i t} \leq \gamma, \\
\mathrm{TFP}_{i t}=\alpha_{0}+Z_{i t} \beta_{2}+\theta_{2} \mathrm{FCF}_{i t}+\mu_{i}+\xi_{i t}, & \text { if } q_{i t}>\gamma,
\end{array}
$$

where $i$ represents province; $i$ represents year; $\mathrm{TFP}_{i t}$ represents high-quality economic development; $Z_{i t}$ represents the set of control variables, namely, investment rate (ITR), population growth rate (PGR), urbanization rate (UBR), and industrialization rate (IDR); $\mathrm{FCF}_{i t}$ represents the financial system; $q_{i t}$ represents the threshold variable (the threshold variables in this paper are financial system (FCF), economic development level (AGDP), and infrastructure (RPC)); $\gamma$ represents threshold value; $\mu_{i}$ represents individual effect; and $\xi_{i t}$ represents independent and identically distributed random disturbance term and is not correlated with $\mathrm{FCF}_{i t}$. The following can be obtained from formula (2):

$$
\begin{aligned}
\operatorname{TFP}_{i t}= & \alpha_{0}+Z_{i t} \beta_{1}+\theta_{1} F C F_{i t} I\left(q_{i t} \leq \gamma\right)+\theta_{2} F C F_{i t} I\left(q_{i t}>\gamma\right) \\
& +\mu_{i}+\xi_{i t}
\end{aligned}
$$

Among them, the indicative function $I($.$) is$

$$
\begin{aligned}
& I\left(q_{i t} \leq \gamma\right)=\left\{\begin{array}{ll}
1, & \text { if } q_{i t} \leq \gamma \\
0, & \text { if } q_{i t}>\gamma
\end{array} ;\right. \\
& I\left(q_{i t}>\gamma\right)= \begin{cases}1, & \text { if } q_{i t} \leq \gamma \\
0, & \text { if } q_{i t}>\gamma\end{cases}
\end{aligned}
$$

According to the panel threshold regression theory of Hansen [43], a certain variable is selected as the threshold variable. If the searched threshold value is $\gamma$, the estimated minimum threshold value of residual sum of squares $\widehat{\gamma}$ is obtained, that is, $\hat{\gamma}=\arg _{\gamma} \min S_{1}(\gamma)$. Then, the significance test of the threshold is carried out. The objective is whether the parameters estimated by the two groups of samples and models divided by the threshold value are significantly different. The basic idea is to simulate a set of dependent variable sequences, get residual terms, calculate LM statistics, obtain $P$ value based on the bootstrap method, and get significance level. After the threshold effect of the variation is determined, the confidence interval of the threshold value is further determined and LR statistics are constructed to estimate the consistency between the threshold value $\widehat{\gamma}$ and the real threshold value $\gamma$.

Similarly, a two-threshold model can be set as follows: 
TABLe 3: Descriptive statistics of variables.

\begin{tabular}{lccccc}
\hline & Meaning & Mean value & Maximal value & Minimal value & Standard deviation \\
\hline TFP & High-quality economic development & 1.946 & 22.188 & 0.893 & 1.595 \\
FCF & Financial system & 2.262 & 1.239 & 0.081 & 0.177 \\
AGDP & Economic development level & 4.053 & 12.906 & 0.623 & 2.389 \\
IDL & Industrial structure & 4.401 & 11.840 & 0.768 & 2.001 \\
RPC & Infrastructure & 1.266 & 11.939 & 0.117 & 1.796 \\
ITR & Investment rate & 0.705 & 1.479 & 0.237 & 0.235 \\
PGR & Population growth rate & 5.321 & 11.781 & -0.006 & 2.661 \\
UBR & Urbanization rate & 0.534 & 0.896 & 0.275 & 0.136 \\
IDR & Industrialization rate & 0.466 & 0.614 & 0.192 & 0.082 \\
\hline
\end{tabular}

$$
\begin{array}{ll}
\mathrm{TFP}_{i t}=\alpha_{0}+Z_{i t} \beta_{1}+\theta_{1} F C F_{i t}+\mu_{i}+\xi_{i t}, & \text { if } q_{i t} \leq \gamma_{1}, \\
\mathrm{TFP}_{i t}=\alpha_{0}+Z_{i t} \beta_{2}+\theta_{2} F C F_{i t}+\mu_{i}+\xi_{i t}, & \text { if } \gamma_{1}<q_{i t} \leq \gamma_{2}, \\
\mathrm{TFP}_{i t}=\alpha_{0}+Z_{i t} \beta_{3}+\theta_{3} F C F_{i t}+\mu_{i}+\xi_{i t}, & \text { if } q_{i t}>\gamma_{2} .
\end{array}
$$

The following can be obtained from formula (5):

$$
\begin{aligned}
\mathrm{TFP}_{i t}= & \alpha_{i}+Z_{i t} \beta_{1}+\theta_{1} \mathrm{FCF}_{i t} I\left(q_{i t} \leq \gamma\right)+\theta_{2} \mathrm{FCF}_{i t} I\left(\gamma<q_{i t} \leq \gamma\right) \\
& +\theta_{3} \mathrm{FCF}_{i t} I\left(q_{i t}>\gamma\right)+\mu_{i}+\xi_{i t}
\end{aligned}
$$

Among them, the indicative function $I($.$) is$

$$
\begin{aligned}
I\left(q_{i t} \leq \gamma\right) & = \begin{cases}1, & \text { if } q_{i t} \leq \gamma_{1}, \\
0, & \text { if } q_{i t}>\gamma_{1},\end{cases} \\
I\left(\gamma_{1}<q_{i t} \leq \gamma_{2}\right) & = \begin{cases}1, & \text { if } \gamma_{1}<q_{i t} \leq \gamma_{2}, \\
0, & \text { if } q_{i t} \leq \gamma_{1} \text { 或 } q_{i t}>\gamma_{2},\end{cases} \\
I\left(q_{i t}>\gamma_{2}\right) & = \begin{cases}1, & \text { if } q_{i t} \leq \gamma_{2}, \\
0, & \text { if } q_{i t}>\gamma_{2} .\end{cases}
\end{aligned}
$$

The multithreshold model can be deduced in this way and will not be described here.

\section{Empirical Analysis}

5.1. Matching Test Results of Financial System and HighQuality Economic Development. The results in Table 4 show that the impact of the financial system, investment rate, and industrialization rate on high-quality economic development is negative at the significance level of $10 \%, 5 \%$, and $1 \%$, respectively. The impact of population growth rate and urbanization rate on high-quality economic development is positive at the significance level of $10 \%$ and $5 \%$, respectively. Therefore, in order to explore the nonlinear relationship between the financial system and the high-quality economic development, threshold regression is carried out on them.

5.2. Determination of Threshold Number and Threshold Value. The threshold variables in this paper are financial system (FCF), economic development level (AGDP), infrastructure (RPC), and industrial structure (IDL), respectively. Its basic principle is to use the "Grid Search" of Hansen to continuously give candidate threshold values and grid the range of candidate threshold values at a level of 0.0025 [43]. All the obtained grid points are taken as candidate threshold values, and then the residual sum of squares of the corresponding model is obtained by regression. Meanwhile, the candidate threshold value with the smallest residual sum of squares of the model is taken as the true threshold value of regression estimation, and the significance of the number of threshold variables is tested by repeated sampling of bootstrap for 300 times.

It can be seen from the results in Tables 5 and 6 that the threshold variable of financial system passes the single threshold test at the level of $1 \%$ and the double threshold significance test at the level of $5 \%$, respectively, with threshold values of 0.1377 and 0.1355 , respectively; The threshold variable of economic development level passes the single threshold test at the level of $1 \%$, and the threshold value is 0.1409 . The threshold variable of infrastructure passes the single threshold significance test at the level of $1 \%$, and the threshold value is 0.1167 . The threshold variable of industrial structure passes the single threshold test at the level of $1 \%$ and the double threshold significance test at the level of $10 \%$, with threshold values of 0.1408 and 0.1364 , respectively. The threshold number of each threshold variable and the confidence interval of the threshold value are demonstrated in Table 6.

5.3. Threshold Regression Estimation Results. In Table 7, the results of linear regression model show that the financial system passes the significance test at the level of $10 \%$, and the coefficient is negative, indicating that the high-quality economic development decreases by 0.89802 percentage points for every one percentage point increase in the financial system. In the threshold regression results, when the financial system index is less than 0.1355 , it passes the significance test at the level of $5 \%$, and the coefficient is positive, indicating that the high-quality economic development increases by 8.22193 percentage points for every percentage point increase in the financial system index. When the financial system index is greater than 0.1355 and less than 0.1377 , it passes the significance test at the level of $1 \%$, and the coefficient is positive, indicating that the highquality economic development increases by 39.87714 percentage points for every percentage point increase in the financial system index. When the financial system index is greater than 0.1377 , it passes the significance test at the level of $1 \%$, and the coefficient is negative, indicating that the high-quality economic development decreases by 0.49330 percentage points for every percentage point increase in the 
TABLE 4: Matching between financial system and high-quality economic development.

\begin{tabular}{cccccc}
\hline & FCF & ITR & PGR & UBR & IDR \\
\hline \multirow{2}{*}{ TFP } & $-0.89802^{*}$ & $-1.36559^{*}$ & $0.31080^{* *}$ & $8.55228^{* *}$ & $(3.10)$ \\
& $(-1.98)$ & $(-1.97)$ & $(3.04)$ & $(-6.04)$ \\
\hline
\end{tabular}

Note. $*, * *$, and $* * *$ mean passing the significance level test at the level of $10 \%, 5 \%$, and $1 \%$, respectively, and statistics of $t$ are in brackets.

TABLE 5: Significance test of threshold number.

\begin{tabular}{|c|c|c|c|c|c|c|}
\hline Threshold variable & Model name & $F$-statistics & $P$ value & $10 \%$ & $5 \%$ & $1 \%$ \\
\hline \multirow{3}{*}{ FCF } & Single threshold & 41.51 & 0.0033 & 19.5630 & 24.0403 & 32.7073 \\
\hline & Double threshold & 39.54 & 0.0200 & 21.6297 & 29.3412 & 51.1382 \\
\hline & Triple threshold & 14.64 & 0.3800 & 42.7008 & 62.6391 & 109.2597 \\
\hline \multirow{2}{*}{ AGDP } & Single threshold & 187.18 & 0.0000 & 45.6444 & 58.7740 & 96.0616 \\
\hline & Double threshold & 11.12 & 0.7200 & 29.4165 & 34.1297 & 87.7959 \\
\hline \multirow{2}{*}{ RPC } & Single threshold & 47.88 & 0.0000 & 25.2811 & 32.5121 & 43.2530 \\
\hline & Double threshold & 1.85 & 1.0000 & 19.3024 & 24.1541 & 35.1465 \\
\hline \multirow{3}{*}{ IDL } & Single threshold & 218.04 & 0.0000 & 21.2039 & 33.3240 & 40.7924 \\
\hline & Double threshold & 29.87 & 0.0600 & 24.7560 & 30.2114 & 43.4546 \\
\hline & Triple threshold & 12.90 & 0.2500 & 15.3707 & 17.0522 & 18.2875 \\
\hline
\end{tabular}

TABle 6: Threshold estimation and confidence interval.

\begin{tabular}{lccr}
\hline Variable & Threshold number & Threshold estimation & 95\% confidence interval \\
\hline \multirow{2}{*}{ FCF } & 1 & 0.1355 & {$[0.1322,0.1434]$} \\
& 2 & 0.1377 & {$[0.1375,0.1399]$} \\
\hline AGDP & 1 & 0.1409 & {$[0.1408,0.1434]$} \\
\hline RPC & 1 & 0.1167 & {$[0.1156,0.1267]$} \\
\hline \multirow{2}{*}{ IDL } & 1 & 0.1364 & {$[0.1359,0.1456]$} \\
& 2 & 0.1408 & {$[0.1387,0.1409]$} \\
\hline
\end{tabular}

Table 7: Parameter estimation results with financial system as threshold variable.

\begin{tabular}{|c|c|c|}
\hline Variable & Linear regression & Threshold regression \\
\hline C & $\begin{array}{c}2.04702 \\
(1.20)\end{array}$ & $\begin{array}{c}0.25270 \\
(0.17)\end{array}$ \\
\hline FCF & $\begin{array}{c}-0.89802^{*} \\
(-1.98)\end{array}$ & \\
\hline $\mathrm{FCF} \leq K_{i 0}$ & & $\begin{array}{l}8.22193^{* *} \\
(2.45)\end{array}$ \\
\hline$g<\mathrm{FCF} \leq \delta$ & & $\begin{array}{l}39.87714^{* * *} \\
(8.60)\end{array}$ \\
\hline $\mathrm{FCF}>K_{i t}=I_{i t}+(1-\delta) K_{i t-1}$ & & $\begin{array}{c}-0.49330^{* * *} \\
(-2.84)\end{array}$ \\
\hline ITR & $\begin{array}{c}-1.36559^{*} \\
(-1.97)\end{array}$ & $\begin{array}{c}-0.89511 \\
(-1.41)\end{array}$ \\
\hline PGR & $\begin{array}{c}0.31080^{* *} \\
(3.04)\end{array}$ & $\begin{array}{c}0.19427^{* *} \\
(2.09)\end{array}$ \\
\hline UBR & $\begin{array}{c}8.55228^{* *} \\
(3.10)\end{array}$ & $\begin{array}{c}9.74416^{* * *} \\
(3.92)\end{array}$ \\
\hline IDR & $\begin{array}{c}-10.98957^{* * *} \\
(-6.04)\end{array}$ & $\begin{array}{c}-9.06780^{* * *} \\
(-5.48)\end{array}$ \\
\hline$F$ & 2.11 & 2.69 \\
\hline
\end{tabular}

Note. $*, * *$, and $* * *$ mean passing the significance test at the level of $10 \%, 5 \%$, and $1 \%$, respectively, and statistics of $t$ are in brackets.

financial system index. From the results of control variable coefficients obtained by linear regression and threshold regression, the investment rate coefficient obtained by threshold regression is not significant. Meanwhile, there is little difference in the coefficients of the other three variables, and the symbols of the coefficients are the same. On the one hand, it demonstrates that population growth rate and urbanization rate have significant positive effects on highquality economic development, while industrialization rate has significant negative effects on high-quality economic 
development. On the other hand, it also verifies that the obtained results are relatively robust. The above results indicate that there is a threshold for the impact of the financial system on high-quality economic development. When it is less than the first threshold, financial credit plays a role such as financial support for enterprises and real estate, and it shows an effective allocation of capital at the macrolevel. When it is between the first threshold and the second threshold, the channel of capital transmission is smoother [6], and the financial system plays a greater role in capital allocation and has a more obvious positive impact on economic growth. When the value is greater than the second threshold, the financial market excessively pursues the development in form and quantity, which creates high profits in the financial industry and too fast development in the real estate and other industries. This forms extensive development, results in unreasonable industrial structure and unbalanced development, and further hampers the highquality economic development, which is also consistent with the negative influence of the investment rate and industrialization rate in the control variables.

In Table 8, the results of the linear regression model show that the economic development level passes the significance test at the level of $1 \%$, and the coefficient is positive, indicating that the high-quality economic development increases by 0.98866 percentage points for every one percentage point increase in the economic development level. In the result of threshold regression, when the economic development level is less than 0.1409 , it passes the significance test at the level of $1 \%$, and the coefficient is positive, indicating that the economic development level is less than 0.1409, and the high-quality economic development increases by 1.11002 percentage points for every percentage point increase in the financial system index. When the economic development level is greater than 0.1409 , it also passes the significance test at $1 \%$ level, and the coefficient is positive, indicating that the high-quality economic development increases by 0.69167 percentage points for every one percentage point increase in the index of financial system. From the control variable coefficient results obtained by linear regression and threshold regression, the investment rate coefficient is not significant, and the population growth rate coefficient obtained by threshold regression is not significant. Meanwhile, there are small differences in the coefficients of the other two variables, and the symbols of the coefficients are the same. There is little variation with the results of control variables in Table 7 , which suggests that the obtained results are relatively stable. The result shows that when the economic development level is less than the threshold value of 0.1409 , the increase of financial system index can promote economic development, and the positive promotion effect is larger. When the economic development level is greater than the threshold value of 0.1409 , the positive promotion effect is smaller although the increase of financial system index can also promote economic growth. The economic development level reflects the macroeconomic operation and economic development of a country or region. The higher the matching between the financial system and economic development is, the more it can promote regional economic growth. Otherwise, it will easily lead to the mismatch of financial resources. In this case, the role of the financial system will be distorted, and the normal state of the financial system cannot be exerted [6].

In Table 9, the results of the linear regression model show that the infrastructure passes the significance test at the level of $1 \%$, and the coefficient is positive, indicating that the highquality economic development increases by 0.40301 percentage points for every percentage point increase in infrastructure. In the result of threshold regression, when the infrastructure is less than 0.1167 , it passes the significance test at the level of $1 \%$, and the coefficient is positive, indicating that the high-quality economic development increases by 0.95535 percentage points for every percentage point increase in the financial system index. When the infrastructure is greater than 0.1167 , it passes the significance test at the level of $5 \%$, and the coefficient is positive, indicating that when the infrastructure is greater than 0.1167, the high-quality economic development increases by 0.41434 percentage points for every percentage point increase in the financial system index. From the control variable coefficient results obtained by linear regression and threshold regression, the investment rate coefficient is not significant. Meanwhile, there are small differences in the coefficients of the other three variables, and the symbols of the coefficients are the same. This is consistent with the previous results, indicating that the obtained results are relatively stable. The above results show that when the infrastructure is less than the threshold of 0.1167 , the increase of the financial system index can promote economic development, and the positive promotion effect is larger. When the infrastructure is greater than the threshold of 0.1167 , the positive promotion effect is smaller although the increase of the financial system index can also promote economic growth. The construction level of transportation infrastructure plays an important role in the flow of regional factors of production and has an impact on regional trade and other economic activities, which not only affects the economic development model but also has a significant impact on regional economic growth and comprehensive economic efficiency [44]. The construction and maintenance of infrastructure projects need financial credit support, while the credit funds for investment in urban construction and public services have large scale, long payback period, low project income, and low enthusiasm of financial institutions, which cannot meet the construction needs [45]. Therefore, when the infrastructure is less than the threshold value, the financial system has the greatest positive role in promoting the high-quality economic development. When it is greater than the threshold value, the development of public services such as infrastructure does not receive enough financial support, thus leading to the slowdown of economic growth.

In Table 10, the results of the linear regression model show that the industrial structure passes the significance test at the level of $1 \%$, and the coefficient is positive, indicating that the high-quality economic development increases by 0.66550 percentage points for every percentage point increase in industrial structure. In the result of threshold regression, when the industrial structure is less than 0.1364 , it passes the significance test at the level of $1 \%$, and the coefficient is positive, indicating that when the industrial structure is less than 
TABLE 8: Parameter estimation results with economic development level as threshold variable.

\begin{tabular}{|c|c|c|}
\hline Variable & Linear regression & Threshold regression \\
\hline$C$ & $\begin{array}{c}8.50930^{* * *} \\
\quad(6.13)\end{array}$ & $\begin{array}{c}5.31708^{* * *} \\
(4.28)\end{array}$ \\
\hline AGDP & $\begin{array}{c}0.98866^{* * *} \\
(14.21)\end{array}$ & - \\
\hline $\mathrm{AGDP} \leq K_{i 0}$ & - & $\begin{array}{c}1.11002^{* * *} \\
(18.04)\end{array}$ \\
\hline $\mathrm{AGDP}>\gamma_{1}$ & - & $\begin{array}{c}0.69167^{* * *} \\
(10.34)\end{array}$ \\
\hline ITR & $\begin{array}{c}0.11457 \\
(0.21)\end{array}$ & $\begin{array}{c}0.24819 \\
(0.52)\end{array}$ \\
\hline PGR & $\begin{array}{c}0.23555^{* *} \\
(2.98)\end{array}$ & $\begin{array}{c}0.13366 \\
(1.93)\end{array}$ \\
\hline UBR & $\begin{array}{c}18.52061^{* * *} \\
(6.35)\end{array}$ & $\begin{array}{c}10.14204^{* * *} \\
(3.81)\end{array}$ \\
\hline IDR & $\begin{array}{c}-4.31029^{* *} \\
(-2.91)\end{array}$ & $\begin{array}{c}-3.84063^{* *} \\
(-2.98)\end{array}$ \\
\hline$F$ & 2.57 & 3.27 \\
\hline
\end{tabular}

Note. $*, * *$, and $* * *$ mean passing the significance test at the level of $10 \%, 5 \%$, and $1 \%$, respectively, and statistics of $t$ are in brackets.

TABLE 9: Parameter estimation results with infrastructure as threshold variable.

\begin{tabular}{|c|c|c|}
\hline Variable & Linear regression & Threshold regression \\
\hline C & $\begin{array}{c}1.45388 \\
(0.86)\end{array}$ & $\begin{array}{c}0.67535 \\
(0.43)\end{array}$ \\
\hline RPC & $\begin{array}{c}0.40301^{* * *} \\
\quad(0.84)\end{array}$ & - \\
\hline $\mathrm{RPC} \leq K_{i 0}$ & - & $\begin{array}{c}0.95535^{* * *} \\
(6.01)\end{array}$ \\
\hline $\mathrm{RPC}>\gamma_{1}$ & - & $\begin{array}{c}0.41434^{* *} \\
(3.31)\end{array}$ \\
\hline ITR & $\begin{array}{c}-1.08178 \\
(-1.57)\end{array}$ & $\begin{array}{c}-0.43531 \\
(-0.69)\end{array}$ \\
\hline PGR & $\begin{array}{c}0.28699^{* *} \\
(2.80)\end{array}$ & $\begin{array}{c}0.21791^{*} \\
(2.31)\end{array}$ \\
\hline UBR & $\begin{array}{c}7.64281^{*} \\
(2.17)\end{array}$ & $\begin{array}{c}8.11976^{*} \\
(2.52)\end{array}$ \\
\hline IDR & $\begin{array}{c}-10.23950^{* * *} \\
(-5.64)\end{array}$ & $\begin{array}{c}-9.09859^{* * *} \\
(-5.46)\end{array}$ \\
\hline$F$ & 2.07 & 2.88 \\
\hline
\end{tabular}

Note. $*, * *$, and $* * *$ mean passing the significance test at the level of $10 \%, 5 \%$, and $1 \%$, respectively, and statistics of $t$ are in brackets.

0.1364 , the high-quality economic development increases by 0.87571 percentage points for every percentage point increase in the financial system index. When the industrial structure is greater than 0.1364 and less than 0.1408 , it passes the significance test at the level of $1 \%$, and the coefficient is positive, indicating that when the industrial structure is greater than 0.1364 and less than 0.1408 , the high-quality economic development increases by 2.20076 percentage points for every one percentage point increase in the financial system index. When the industrial structure is greater than 0.1408 , it passes the significance test at the level of $1 \%$, and the coefficient is positive. From the results of control variable coefficients obtained by linear regression and threshold regression, the investment rate coefficient obtained by both methods is not significant. Meanwhile, there are small differences in the coefficients of the other three variables, and the symbols of the coefficients are all the same, indicating that the results are relatively robust. This is because financial capital will be allocated among various industries.

Only the financial structure suitable for the industrial structure can promote the high-quality economic development. China's industrial structure is dominated by labor-intensive industries, and the tertiary industry is underdeveloped. So far, high-tech industries have developed rapidly, and the tertiary industry has also developed rapidly. In recent decades, the financial system has expanded rapidly in scale. Between the first threshold and the second threshold, the financial support for industrial development is obvious, which makes the economy develop 
TABLE 10: Parameter estimation results with industrial structure as threshold variable.

\begin{tabular}{|c|c|c|}
\hline Variable & $\begin{array}{l}\text { Linear } \\
\text { regression }\end{array}$ & Threshold regression \\
\hline C & $\begin{array}{c}0.19592 \\
(0.12)\end{array}$ & $\begin{array}{c}-1.59241 \\
(-1.62)\end{array}$ \\
\hline IDL & $\begin{array}{c}0.66550^{* * *} \\
(3.89)\end{array}$ & - \\
\hline $\mathrm{IDL} \leq K_{i 0}$ & - & $\begin{array}{c}0.87571^{* * *} \\
\quad(7.24)\end{array}$ \\
\hline$g<\mathrm{IDL} \leq \delta$ & - & $\begin{array}{c}2.20076^{* * *} \\
(17.84)\end{array}$ \\
\hline $\mathrm{IDL}>K_{i t}=I_{i t}+(1-\delta) K_{i t-1}$ & - & $\begin{array}{l}0.42569^{* * *} \\
\quad(4.09)\end{array}$ \\
\hline ITR & $\begin{array}{c}-0.85190 \\
(-1.26)\end{array}$ & $\begin{array}{c}-0.65559 \\
(-1.60)\end{array}$ \\
\hline PGR & $\begin{array}{c}0.26372^{* *} \\
(2.68)\end{array}$ & $\begin{array}{c}0.19682^{* *} \\
(3.27)\end{array}$ \\
\hline UBR & $\begin{array}{c}7.80510^{* * *} \\
(2.88)\end{array}$ & $\begin{array}{c}9.43922^{* * *} \\
(5.74)\end{array}$ \\
\hline IDR & $\begin{array}{c}-8.71465^{* * *} \\
(-4.79)\end{array}$ & $\begin{array}{c}-5.89060^{* * *} \\
(-5.27)\end{array}$ \\
\hline$F$ & 2.52 & 6.83 \\
\hline
\end{tabular}

Note. $*, * *$, and $* * *$ mean passing the significance test at the level of $10 \%$, $5 \%$, and $1 \%$, respectively, and statistics of $t$ are in brackets.

rapidly. After exceeding the second threshold, financial products cannot meet the needs of industrial development, and the promotion to the economy will become smaller.

\section{Conclusions and Policy Recommendations}

Because the financial system needs to adapt to the economic growth stage in size and structure to meet the needs of economic growth [35], different economic growth stages have different requirements for the financial system. Developed countries pay more attention to the stability of the financial system due to their high degree of financial marketization and vulnerability to systemic risks. However, developing countries have the comparative advantages of labor-intensive industries and lower industrial risks, so they pay more attention to the utility and functionality of the financial system. The difference of factor endowment structure determines that there is a threshold effect between financial system and high-quality economic development.

In this paper, the panel data of 30 provinces and autonomous regions in China from 2005 to 2018 are taken as samples, and the financial system, economic development level, infrastructure, and industrial structure are taken as threshold variables to construct a threshold model. Furthermore, the nonlinear relationship between China's financial system and high-quality economic development is studied, and the following conclusions are drawn.

First, the impact of the financial system on the highquality economy presents an inverted U-shaped relationship. The financial system has a threshold for high-quality economic development. Between the first threshold of 0.1355 and the second threshold of 0.1377 , the optimal financial system plays a greater role in the allocation of capital and has a more obvious positive impact on economic growth.
Second, when the economic development level is taken as the threshold variable, the impact of the financial system on the high-quality economy shows a diminishing marginal trend. When the economic development level is less than the threshold value of 0.1409 , the financial system plays a greater role in promoting high-quality economic development. When it is greater than the threshold value, it plays a lesser role. When the level of economic development improves, emerging industries have an increasing demand for funds. The financial market dominated by banks cannot meet the needs of economic transformation. At this time, the proportion of direct financing in the financial system is small, so it is necessary to change the current dominance of banks.

Third, when the infrastructure is taken as the threshold variable, the impact of the financial system on the highquality economy displays a diminishing marginal trend. When the infrastructure is less than the threshold value of 0.1167 , the financial system plays a greater role in promoting high-quality economic development. When the infrastructure is greater than the threshold value, it plays a lesser role. It suggests that the matching degree between the current financial system and infrastructure is not high.

Fourth, when the industrial structure is taken as the threshold variable, the impact of the financial system on the high-quality economy displays an inverted U-shaped trend. That is, when the industrial structure is between the first threshold of 0.1364 and the second threshold of 0.1408 , there is an optimal financial system, which promotes economic growth more obviously.

Based on the aforementioned results, the following policy recommendations are put forward:

First, we should pay more attention to the improvement of the basic functions of the financial system. We should focus on the unbalanced and inadequate development of financial systems in various provinces and cities in China, lay emphasis on developing multilevel capital markets, increase the proportion of direct financing, and constantly adjust and optimize the financial structure. Moreover, we should focus on the "six functions" of finance, such as risk diversification, financing, and supply liquidity, enrich the financial product systems such as investment and financing, capital, and risk management, comprehensively promote the market construction of credit, bonds, and financial derivatives, increase financial instruments, improve the reflection and adjustment of prices to market information, and realize more efficient resource allocation.

Second, we should promote the matching of financial system with local economic development level. From 2015, the state has proposed deleveraging and risk prevention and achieved remarkable results in six years. However, with the increasing openness of the financial industry, domestic and international capital flows become more frequent, so we should be fully alert to the systemic financial risks caused by the impact on industries or enterprises with high leverage ratio, serious mismatch between assets and liabilities, and irregular 
internal control. This requires continuous efforts to improve the financial supervision system, improve the efficiency of supervision, standardize the behavior of financial institutions, focus on financial cross-business, shadow banking, and speculative institutions, establish early warning indicators to prevent problems before they happen, and constantly promote the development level of financial system and local economy.

Third, we should strengthen financial support for infrastructure construction. We should further expand the space of financial support for infrastructure construction, increase financial support for infrastructure construction in noncore areas, actively participate in the strategy of "rural revitalization," and promote the "grid" layout of infrastructure to smooth economic links between regions and open up channels for the flow of resources and factors of production. For areas with relatively developed infrastructure, we should strengthen the participation of the financial system in the "new infrastructure" areas such as the construction of $5 \mathrm{G}$ base stations, big data centers, and industrial Internet and strive to form a new focus for the financial system to support high-quality economic development.

\section{Data Availability}

The data used to support the findings of this study are available from the corresponding author upon request.

\section{Conflicts of Interest}

The authors declare that they have no conflicts of interest.

\section{Acknowledgments}

This research was financially supported by the National Social Science Fund of China (grant no. 18BJY249).

\section{References}

[1] Schumpeter, The Theory of Economic Development, Transaction Pub, Piscataway, NJ, USA, 1983.

[2] H. T. Patrick, "Financial development and economic growth in underdeveloped countries," Economic Development and Cultural Change, vol. 14, no. 2, pp. 174-189, 1966.

[3] R. W. Goldsmith, "Financial structure and development," Studies in Comparative Economics, Yale University Press, New Haven, CT, USA, 1969.

[4] R. I. Mckinnon, Money and Capital in Economic Development, Booking Institution, Washington, DC, USA, 1973.

[5] T. Beck, T. Chen, C. Lin, and F. M. Song, "Financial innovation: the bright and the dark sides," Journal of Banking \& Finance, vol. 72, pp. 28-51, 2016.

[6] L. Sun, X. Niu, and A. Li, "An empirical study on the impact of financial fragility on the real economy," Financial Research, vol. 3, no. 1, pp. 61-69+112, 2004.

[7] P. Marco, "Financial markets and growth: an overview," European Economic Review, vol. 37, no. 2-3, pp. 613-622, 1993.
[8] T. I. Palley, "Financialization: what it is and why it matters," Social Science Electronic Publishing, vol. 26, no. 9, pp. 9-15, 2007.

[9] D. Lorenzo and D. Grechyna, "Financial development, real sector, and economic growth," International Review of Economics \& Finance, vol. 37, pp. 393-405, 2015.

[10] R. O. Oluitan, "Financial development and economic growth in Africa: lessons and prospects," Business and Economic Research, vol. 2, no. 2, 2012.

[11] L. Zhang, "Financial development, technological innovation and real economic growth-an empirical study based on spatial measurement," Research on Financial Economics, vol. 31, no. 1, pp. 14-25, 2016.

[12] M. Kabir Hassan, B. Sanchez, and J. S. Yu, "Financial development and economic growth: new evidence from panel data," The Quarterly Review of Economics and Finance, vol. 51, no. 1, pp. 88-104, 2011.

[13] J. Lin and R. Yang, "Mechanism analysis of financial stability and economic growth-based on two groups of data of emerging market countries and developed countries," Financial Research, vol. 37, no. 2, pp. 49-59, 2011.

[14] F. Allen and D. Gale, "Financial contagion," Journal of Political Economy, vol. 108, no. 1, pp. 1-33, 2000.

[15] F. Eschenbach, "Finance and growth: a survey of the theoretical and empirical literature," 2004. Tinbergen Institute Discussion Paper No. TI 2004-039/2.

[16] J. H. Boyd and B. D. Smith, "The evolution of debt and equity markets in economic development," Economic Theory, vol. 12, no. 3, pp. 519-560, 1998.

[17] U. K. Hicks, "Economic and financial problems of metropolitan areas," Zeitschrift für Nationalokonomie, vol. 29, no. 12, pp. 1-18, 1969.

[18] S. Chen, Y. Wang, and Y. Tang, "Analysis of China's financial instability and its impact on macroeconomic asymmetry," International Finance Research, vol. 6, no. 6, pp. 56-66, 2013.

[19] W. Yang, J. Yu, and K. Li, "Allocation of financial resources, technological progress and high-quality economic development," Financial Research, vol. 2, no. 12, pp. 75-94, 2020.

[20] F.-S. Hung, "Explaining the nonlinear effects of financial development on economic growth," Journal of Economics, vol. 97, no. 1, pp. 41-65, 2009.

[21] C. Stephen and E. Kharroubi, "Reassessing the impact of finance on growth," Bis Working Papers, 2012.

[22] F. Zilibotti, "Endogenous growth and intermediation in an "Archipelago" economy," The Economic Journal, vol. 104, no. 423, pp. 462-473, 1994.

[23] Y. Yang, "Financial development and economic growth-based on the analysis of threshold variables of China's financial development," Financial Research, vol. 14, no. 2, pp. 59-71, 2014.

[24] Y. Liu, M. Huang, and C. Bai, "Natural resources and economic growth-based on the threshold effect of financial development," Journal of Natural Resources, vol. 30, no. 12, pp. 1982-1993, 2015.

[25] S. Mihci, "Finance-growth nexus: a threshold effect," Ekonomický Časopis, vol. 54, no. 8, pp. 830-844, 2006.

[26] L. G. Deidda, "Interaction between economic and financial development," Journal of Monetary Economics, vol. 53, no. 2, pp. 233-248, 2006.

[27] M. Graff and A. Karmann, "What determines the financegrowth nexus? empirical evidence for threshold models," Journal of Economics, vol. 87, no. 2, pp. 127-157, 2006. 
[28] P. L. Rousseau and P. Wachtel, "What is happening to the impact of financial deepening on economic growth?" Economic Inquiry, vol. 49, no. 1, pp. 276-288, 2011.

[29] E. Prasad, K. Rogoff, S. J. Wei, and M. Ayhan Kose, "Effects of financial globalization on developing countries: some empirical evidence," India's and China's Recent Experience with Reform and Growth, pp. 201-228, Palgrave Macmillan, London, UK, 2005.

[30] G. Bekaert, C. R. Harvey, and C. Lundblad, "Emerging equity markets and economic development," Journal of Development Economics, vol. 66, no. 2, pp. 465-504, 2001.

[31] L. Zhang, G. Ran, and C. Qiu, "Regional financial strength, FDI spillover and real economic growth-a study based on panel threshold model," Economic Sciences, vol. 2, no. 6, pp. 76-89, 2014.

[32] J. Luo, "Financial development threshold, FDI and regional economic growth mode," World Economic Research, vol. 11, no. 4, pp. 107-118+136, 2016.

[33] Y. Liu and X. Li, "Financial cycle, financial fluctuation and China's economic growth-a study based on the provincial panel threshold model," Statistical Research, vol. 36, no. 10, pp. 74-86, 2019.

[34] Y. Zhang and G. Wang, "Research on the unbalanced relationship between financial development and real economic growth-based on double threshold regression empirical analysis," Contemporary Finance \& Economics, vol. 1, no. 6, pp. 45-54, 2015.

[35] J. Cheng and L. Shou, "Financial stability, financial development and economic growth," Social Scientist, vol. 21, no. 3, pp. 61-63, 2008.

[36] H. Miao and H. Zhou, "Comparison of economic relations and hierarchical structure among three major urban agglomerations in China-analysis based on comprehensive gravity model," Economic Geography, vol. 37, no. 6, pp. 52-59, 2017.

[37] S. Liu and A. Hu, "Transportation infrastructure and China's regional economic integration," Economic Research, vol. 46, no. 3, pp. 72-82, 2011.

[38] X. Chen and L. Deng, "Does the government-led regional integration strategy drive high-quality economic development?-investigation from the perspective of industrial structure optimization," Journal of Jiangxi University of Finance and Economics, vol. 9, no. 01, pp. 43-54, 2019.

[39] C. Zhang and C. Zhong, "Financial innovation, industrial structure change and high-quality economic development," Jianghan Forum, vol. 12, no. 4, pp. 5-16, 2021.

[40] J. Zhang, G. Wu, and J. Zhang, "Estimation of China's provincial physical capital stock: 1952-2000," Economic Research Journal, vol. 7, no. 10, pp. 35-44, 2004.

[41] D. T. Coe and E. Helpman, "International R\&D spillovers," European Economic Review, vol. 39, no. 5, pp. 859-887, 1995.

[42] X. Li, "Capital flow, policy uncertainty and financial stability," Shanghai Finance, vol. 4, no. 2, pp. 30-38, 2019.

[43] B. E. Hansen, "Threshold effects in non-dynamic panels: estimation, testing, and inference," Journal of Econometrics, vol. 93, no. 2, pp. 345-368, 1999.

[44] B. Cui, X. Yang, and B. S. Cui, "Spatial spillover effect of transportation infrastructure on regional economic growth," Urban Issues, vol. 264, no. 7, pp. 48-59, 2017.

[45] $\mathrm{H}$. Hu and S. Chen, "Innovative financing model to solve the financing dilemma of new urbanization," Economic Trends, vol. 3, no. 7, pp. 57-69, 2014. 